\title{
Patterns on the Embroidered Textiles Unearthed from the Silk Road I: Animal Pattern
}

\author{
Kuang Yanghua ${ }^{1} \&$ Cui Rongrong ${ }^{1}$ \\ ${ }^{1}$ Jiangsu Intangible Cultural Heritage Research Base, Textile \& Clothing College, Jiangnan University, Jiangsu, \\ China \\ Correspondence: Kuang Yanghua, Jiangsu Intangible Cultural Heritage Research Base, Textile \& Clothing \\ College, Jiangnan University, 1800 Lihu Avenue, Wuxi, Jiangsu Province, 214122, China. Phone: \\ 86-139-2110-1775. E-mail: tinakyh2005@aliyun.com
}

Received: September 9, 2015 Accepted: October 12, 2015 Online Published: November 20, 2015

doi:10.5539/ass.v11n27p246 URL: http://dx.doi.org/10.5539/ass.v11n27p246

\begin{abstract}
Based on the archaeological evidences from the Silk Road, this paper reviews animal pattern on the embroidered textiles of the Han and Tang dynasties (2ndC BC- 9thC AD). The evidences show that animal pattern is widely found on the embroidered textiles unearthed from the graveyards or ancient sites along the Silk Road and particularly rich in variety. Generally, animals on the embroideries from the Silk Road can be categorized into animals of the real world and animals of the imaginary world. The first group consists of a range of real animals, including birds and butterflies which are usually flying in the sky or among the flowers, herbivorous animals like horses, antelopes, deer (especially reindeers) and yaks and carnivorous animals like tigers which are regular seen on the grasslands and aquatic animals like fish and turtles. The second group includes imaginary animals which play an important role in Chinese mythology like phoenixes, dragons and suanni etc. and significant legendary creature in Central Asian mythology like griffins. Besides, historical documents provide more information about animal pattern adopted by embroidered textiles than we have seen on archaeological evidences.
\end{abstract}

Keywords: animal pattern, embroidery, the Silk Road

As a common motif, although not as common as plant pattern, animal pattern is widely found on the embroidered textiles from Shanpula, Niya, Zhaguluke, Astana in Xinjiang province, the Mogao Grottoes in Gansu province, Dulan or neighboring areas in Qinghai province, Famen Temple in Shaanxi province and Noin-Ula in Mongolia. It is particularly rich in variety.

\section{Animals of the Real World}

(1) Birds

Most of the embroidered birds can't be identified. However, they are nearly always closely connected to flowers. From the embroidered textiles of the late Western Han dynasty (late 1stC BC-early 1stC AD) found in Noin-Ula to the embroidered textiles of the Han and Jin dynasties (2ndC BC-early 4thC AD) found at Niya and Astana, then to the embroidered textiles of the Tang dynasty (early 7thC-9thC) unearthed from the Famen Temple and the Mogao Grottoes, it is obvious that in most cases, birds appear together with flowers. In the Tang dynasty, birds and flowers became a stylized pattern - sometimes birds are enclosed in flowers, sometimes birds are flying in between sprays and sometimes they are holding sprays. Birds on the embroidered textiles from Noin-Ula are executed in satin stitch with wool threads. They are in a naturalistic style, for example, the birds in Figure 1 are large in size, with hooked claws, long tails and outspread wings. Birds on the embroidered textiles from Xinjiang and Gansu are mostly executed in chain stitch with silk threads. Differ from those on textiles found in Noin-Ula, they are usually simple in style. The embroidered borders on a piece of underwear found at Niya show a cute bird: bearing three feathers on head, with sharp beaks, big eyes, outspread claws, curly bodies and wings and long tails (Figure 2a). An embroidered vest unearthed from Astana bears another cute bird: small in size, with round heads, sharp beaks and crescent-shaped bodies (Figure 2b, 2c, 2d and 2e). Some birds are even simpler, for example, the birds on an embroidered border from Wuwei (Figure 2d) and the bird enclosed in flowers on an embroidered piece from Qinghai now in the China National Silk Museum collection (Figure 2g). Birds on the embroidered textiles found at the Mogao Grottoes are mainly executed in satin stitch with silk threads in different colors, sometimes they are even embroidered with gold threads (Zhao, 2007, p. 229), which matches 
the description of cujinxiuin the poems of the Tang dynasty. They are generally in a naturalistic style, especially when they serve as the leading pattern.

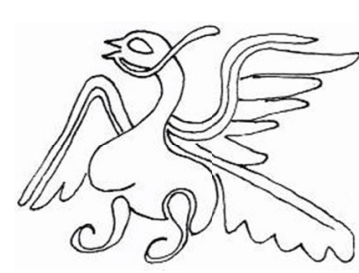

1a

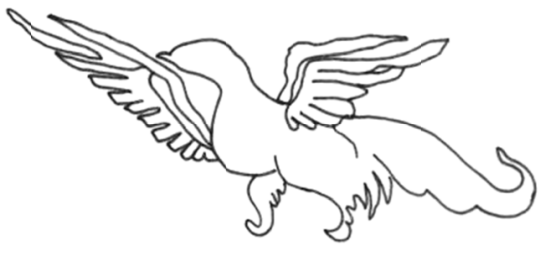

$1 \mathrm{~b}$

Figure 1. Birds on the embroidered textiles found in Noin-Ula

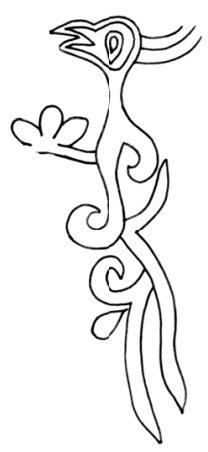

$2 \mathrm{a}$

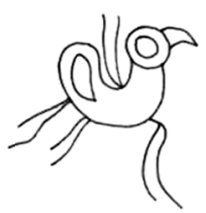

$2 b$

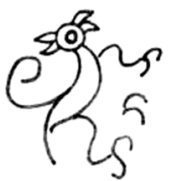

$2 \mathrm{~d}$

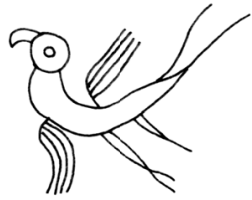

$2 \mathrm{c}$

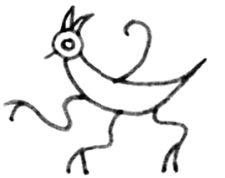

$2 \mathrm{e}$

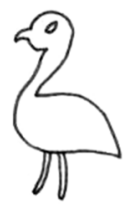

$2 f$

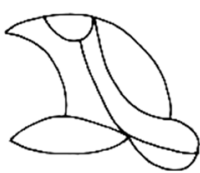

$2 \mathrm{~g}$

Figure 2. Birds on the embroidered textiles found in Xinjiang, Gansu and Qinghai

\section{(2) Butterflies}

As a pattern, butterfly appears as late as the Tang dynasty, especially during the period of the late Tang to Five Dynasties (9thC-10thC). It usually combines with flowers and flying birds to create the scene of a spring day. They are several examples of embroidered butterflies. A sutra wrapper found in the underground repository of the Famen Temple shows a simple butterfly, in between two beautiful phoenixes, being executed in satin and couching stitches with colored silk threads and gold threads (Wang, 2001, p. 122, pl. 17, fig. 3); a piece from Cave 17 also shows a simple butterfly but it is more colorful than the previous one (Zhao, 2007, p. 224); a piece in the collection of China National Silk Museum bears vivid flowers and butterflies, both of which are in a naturalistic style (China National Silk Museum \& State History Museum in Moscow, 2007, pp. 96-97).

\section{(3) Horses}

Horse appears on an embroidered wool fragment from Noin-Ula. Originally, there have been three men and three horses. The horse on the left side turns it head and glances back, with reins, and there is a medallion enclosing a simple quartrefoil at the top end of a foreleg. The horse in the middle shows its head and forelegs, also with reins. The horse in the right side has lost its body; the bowed neck and opened mouth suggest that it is grazing (Rudenko, 1969). The pattern on this piece is in a naturalistic style and executed with strongly twisted wool threads on a wool textile, all of which are quite different from embroideries found in Central China, therefore, it is probably a product from the West. Horse has not yet been found on embroideries from Central China, however, in historical documents it does appear. For example, in Xin Tang shu [New Book of Tang History] it is recorded that some honor guard members in formal occasions at imperial court wear red vest embroidered with wild horses (Song \& Ouyang, 1975, p. 481).

\section{(4) Antelopes}

Antelope appears on the embroidered borders of a garment from Shanpula. Running reindeers and antelopes are 
alternately filled in an S-shaped frame. The antelopes are large in scale, with a long sharp curving horn on head and an upturned hind hoof at back. There are two long strips still can't be identified, one is on one forehoof, the other is below the belly (Figure 3). One antelope has volute-shaped pattern decorated at the joints on the body (Yu, 2010, pp. 169-171). Antelope is also favored by other textiles from Shanpula, for example, on a wool tapestry we see an antelope, with similar head but not as large as those on the embroidered piece (Xinjiang Cultural Relics Administration Bureau et al, 1999, p. 45, fig. 0068). Antelope with an upturned hind hoof also appears on a saddle pad found at Pazyryk Cemetery in Russia, it is griped by a monster with reindeer body and eagle hooked beaks (probably griffin) (Королькова, 2006, p. 109). On the body of the host of Pazyryk Cemetery there is another similar antelope, showing totally upturned hind half body (Ma, 2005, p. 169). The pattern of antelope on textiles from Shanpula indicates the influence from the culture of the grasslands in the North.

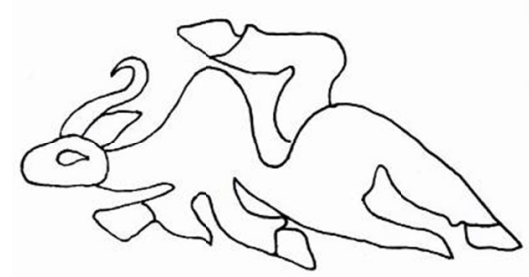

Figure 3. Antelope on the embroidered textiles found in Shanpula

\section{(5) Deer}

Reindeer is found on the embroideries from Noin-Ula and Shanpula. An embroidered carpet from Noin-Ula shows two kinds of animal pattern, one of which shows an eagle-like animal (probably griffin) biting a reindeer. The reindeer is easy to be identified, being large in scale, with four hooves and long branch-shaped antlers (Figure 4a). Pattern of this sort can be considered as a beast-style pattern and has a relationship with the culture of Skythia and Siberia. Running reindeers have also been found on the embroidered borders of a garment from Shanpula but in a more abstract style, showing a slightly pointed head, large branch-shaped antlers and an upturned hind hoof (Figure $4 \mathrm{~b}$ ). A grazing reindeer appears on an embroidered bracer from the same graveyard, also being larger in size (Yu, 2010, pp. 169-171). Reindeer pattern on the embroideries from Shanpula shows an influence from the culture of the grasslands in the North. Reindeer is also common to see on the tapestry from Shanpula, indicating the popularity of this pattern in this area (Museum of Xinjiang Uygur Autonomous Region \& Xinjiang Institute of Archaeology, 2001, pp. 211-212, figs. 406-1 and 407-1). Sika deer (cervus nippon) usually appears in Central China therefore it is found on the embroideries from the South. An exquisite piece from Cave 17 at the Mogao Grottoes in Dunhuang shows a running female sika deer, being small in size, with a short tail, showing pots on body and with no antler (Zhao, 2007, p. 224). On another fragmented piece remains a head of male sika deer, showing beautiful towering antlers (Zhao, 2007, p. 223). Deer on the previous two pieces are in a naturalistic style, which is typical during the period from Tang to Five Dynasties (early 7thC-10thC). In addition, sika deer is also found in the murals of Dunhuang (Duan, 2002, vol. 8, fig. 228).

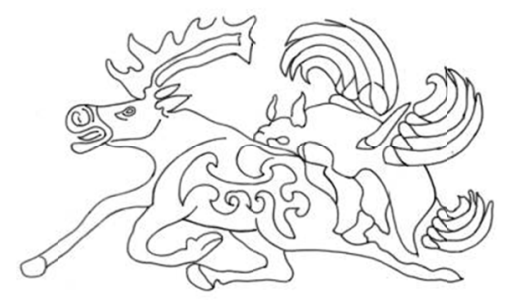

$4 \mathrm{a}$

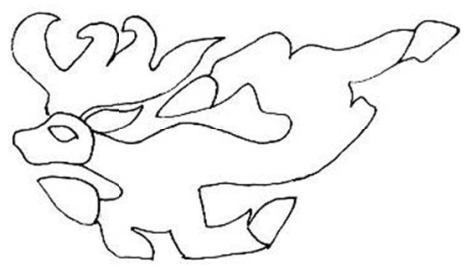

$4 \mathrm{~b}$

Figure 4. Reindeers and griffin on the embroidered textiles found in Noin-Ula and Shanpula

(6) Yaks

Yak is found on an embroidered carpet from Noin-Ula which we have discussed above. There are two kinds of 
animal pattern on this carpet, one shows an eagle-like animal (probably griffin) biting a reindeer and the other shows a monster similar to horse but with several eagle heads (also probably griffin) biting a yak. The yak is extraordinary large in size, with four strong hooves and two sharp horns. It is struggling, baring its teeth and perking up its tail (Figure 5). This carpet should have been a product created by the Huns (Ma, 2005, p. 57).

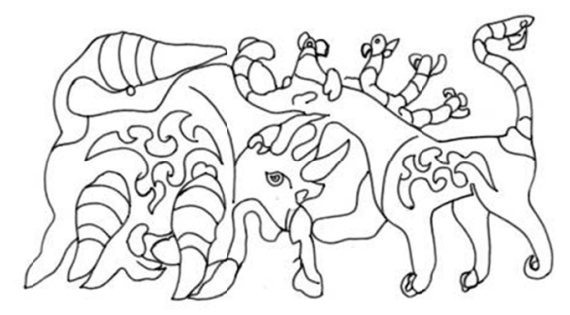

Figure 5. Yak and griffin on an embroidered carpet from Noin-Ula

\section{(7) Tigers}

Tiger is a large carnivore in Asia. Tiger is not common to see on embroideries, we have only got a few examples. An embroidered quilt (now in tatters) from Noin-Ula shows a heart-shaped cloud and on the upper left side of the cloud there is a tiger (Figure 6a), which is just opposite to the dragon depicted in Figure 8a. It is a typical pattern of tiger, having a bouncing walk, showing round head, short tail, strong legs and tiger stripes on the body (Лубо-Лесниченко, 1961, pl. XLIV). Another piece from Noin-Ula bears a quite different tiger, showing a rectangular tiger body (probably indicating tiger skin), with two heads respectively at the top and bottom. The heads are rather similar to lions, with canine teeth, long whiskers and standing ears or horns. There are feet below heads and each has three claws (Umehara, 1960, fig. 48). An embroidered vest from Astana shows a snake-shaped tiger, with S-shaped body, round head, long tongue and wings (Figure 6b) (Kuang, 2013, p. 269, no. 81). It is similar to the tiger on a bronze mirror from Niya (Zhao \& Yu, 2000, p. 90). An embroidered piece of the Northern Dynasties (late 3rdC-late 5thC) collected by Chris Hall also shows a pattern of tiger, which is similar to that in Figure6a but the tiger is up rearing on its hind legs (Arthur M. Sackler Museum of Art and Archeology, PKU \& China National Silk Museum, 2009, p. 17). Embroidered tiger is also described in the poems of the Tang dynasty, for example in a poem written by $\mathrm{Li} \mathrm{He}$ it is described the pattern of tiger embroidered with gold threads on fur (Peng, 1986, vol. 393, p. 981).

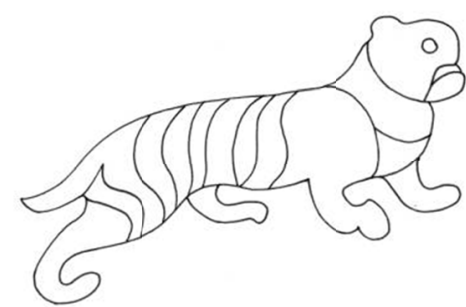

$6 a$

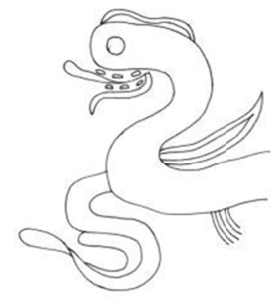

$6 \mathrm{~b}$

Figure 6. Tigers on the embroidered textiles found in Noin-Ula and Astana

\section{(8) Fish and turtles}

Fish appears on two wool embroidered hangings from Noin-Ula. In a lozenge frame consisting of florets and vines fish and turtles (on one piece) or birds (on the other piece) are alternately filled. The fish have big head, S-shaped body and obvious fins (Figure 7a), being similar to the fish on the painted pottery of an early period found in Gansu (Zhang, 2002, p. 10). The turtle each has a small and pointed head, four long antennas, a round shell decorated with diamonds and four outspread feet (Figure 7b). Fish and turtles on these two pieces are in a naturalistic style and executed in satin stitch with wool threads on wool textiles, therefore they should not have been produced in Central China but in the West. However, fish and turtle do appear on other relics from Central China, for example, on the top of a pottery kitchen range found in the Mausoleum of Western Han Emperor Liu 
Qi (188 BC-141 BC) there are a fish and a turtle (Shaanxi Provincial Institute of Archaeology, 2001, p. 90). And in the Tang dynasty, a lady embroidered a poem in the shape of a turtle and dedicated it to the Emperor to beg to let her husband come back from the battlefield (Peng, 1986, vol. 799, p. 1961).

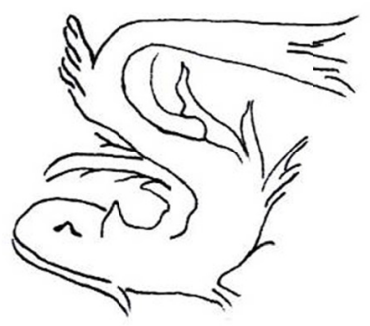

$7 \mathrm{a}$

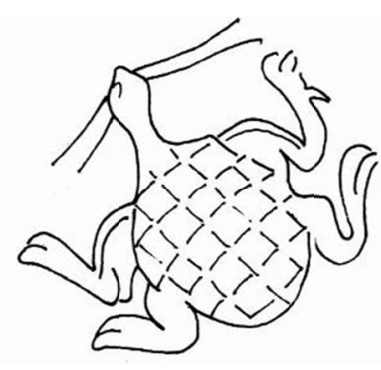

$7 \mathrm{~b}$

Figure 7. Fish and turtle on the embroidered textiles found in Noin-Ula

\section{Animals of the Imaginary World}

(1) Phoenixes, wuseniao (five-colored birds) and double-headed birds

Bird on embroidered textiles is usually hard to be identified except phoenix and wuseniao. A square cloth from the underground repository of Famen Temple originally has a roundel comprising two whirling phoenixes in the centre and four flying phoenixes on the four corners. The phoenixes on the corners have long tails and beautiful feathers, with wings outspread, heads toward the centre and beaks holding leaves (Wang, 2001, p. 122, pl. 17, Figure 3). Another example is from the Mogao Grottoes, the fragment only shows two outspread wings and a long tail of a phoenix (Zhao, 2010, p. 224).

Phoenix should have been favored by embroidered textiles in the Tang dynasty. In the poems of this period, phoenix frequently appears, for example, in a poem Colored Phoenix written by Zhao Gu it described that two flying phoenixes are embroidered on a curtain (Peng, 1986, vol. 27, p. 103), and in a poem Swallow written by Teng Bai it described that a beauty is embroidering a phoenix with a gold needle (Peng, 1986, vol. 731, p. 1833). According to some poems, embroidered phoenix often appear together with a bird known as xichi or a parrot (probably created by another technique), for example in a poem written by Zhang Bi it described that a cushion made of samite woven with red xichi and a robe made of gauze embroidered with phoenix (Peng, 1986, vol. 898, p. 2185) and in a poem written by Weng Tingjun it described that a beauty in a dress with an embroidered phoenix on her breast is holding a gold parrot in her hand (Peng, 1986, vol. 891, p. 2166). Phoenix is also executed with gold threads, which has been described in the poems written by Shen Yazhi (Peng, 1986, vol. 493, p. 1245), Situ Kong (Peng, 1986, vol. 633, p. 1598) and Wen Tingjun (Peng, 1986, vol. 891, p. 2166).

The birds on an embroidered piece unearthed from Northwestern China or neighboring areas dated back to the Tang dynasty in the collection of the Abegg Foundation have been identified as wuseniao (Zhao, 1999, p. 115). They are embroidered with threads in five colors - white, yellow, red, blue and green, which are very traditional in China. Jin-silk with wuseniao is recorded in the documents from Dunhuang and has been proved by a piece found at Dulan in Qinghai province. The bird on jin-silk from Dunlan is quite similar to those on this embroidery, showing round body, small crest, short tail, strong claws and long curly feathers at wings. Birds of this sort show a typical influence from Central Asia, especially the one on jin-silk from Dulan. It is enclosed in a wreath of petals, standing on a pearl pedestal and holding a pearl ribbon in its beaks (Zhao, 1999, p. 114). Similar birds are also found on jin-silk in Cleveland Museum of Art and Cathedral of Aachen collections (Zhao, 1999, p. 116).

Double-headed birds are also found on the embroidered textiles unearthed from Zhagunluke and Astana (Zhao, 2005, p. 165, fig. 3-3-18; Li, 2006, pp. 94-95), but it is quite different from double-headed eagles in the West.

(2) Dragons

Dragon plays an important role in Chinese myth. In ancient Chinese documents, dragon is described as a scaly beast which can be long or short, big or small. According to the records we only get a hazy idea about dragon. Dragon also appears on embroidered textiles unearthed from the Silk Road, from which we can have a better understanding of this mythical creature. On an embroidered quilt (now in tatters) found in Noin-Ula there originally are two walking dragons: one in the middle of the quilt, being filled in a heart-shaped cloud, with 
wings and scales (Figure 8a); the other is at the right corner of the quilt, showing long jaws and with whiskers on the upturned upper jaw, being covered with scales and with wings at the middle of the body (Лубо-Лесниченко, 1961, pl. LI). According to historical documents, walking dragons are known as yinglong. An embroidered vest of the Sixteen Kingdoms (4thC-early 5thC) period from Astana shows a much simpler dragon, being short, with two long jaws including an upturned upper jaw, a long tongue and four legs with claws. There is a curly line stretching from the back of the dragon, probably indicating wings (Figures. 8b and 8c). Dragons on another vest from the same graveyard are more close to the traditional dragon in Central China. They are long and similar to snake but have four legs, also with long and upturned jaws and curly things stretching from their backs (Figures. $8 \mathrm{~d}$ and 8e). One has branch-shaped horns on its head (Figure 8e) (Kuang, 2013, p. 269, no. 81). On an wool embroidery from Shanpula we see another fantastic animal: its head is similar to phoenix, with hooked beaks and four feathers on the top; its body looks like snake, being decorated with a geometrical pattern (probably indicating leaves) which is common on the wool tapestry from Shanpula (Figure 8f) (Museum of Xinjiang Uygur Autonomous Region \& Xinjiang Institute of Archaeology, 2001, pp. 219-220, figs. 414-415). The pattern on the textiles found in Shanpula has a close relation to the art of Central China. It is quite similar to the pattern of dragon on a lacquer work of the Chu State (Chen, 1996, fig. 94), and an animal with similar phoenix head on the tapestry from Shanpula has been identified as dragon (Museum of Xinjiang Uygur Autonomous Region \& Xinjiang Institute of Archaeology, 2001, p. 214, fig. 409), therefore this animal may also represent dragon. Generally, dragon during this period can be categorized into two groups, one looks like a walking beast, showing a short body with a dragon head; the other looks like snake, showing a long S-shaped body but with four legs (Zhang, 2004, pp. 121-122).

Dragon also appears on the embroidered silks from the Mogao Grottoes in Dunhuang. We get two examples from Cave 17. A group of simple gauze fragments show dragon executed with gold threads on a purple ground, however, they are much in tatters and it is hard to reconstruct the original pattern (Zhao, 2007, p. 231). A light red gauze fragment embroidered with flowers still survives a dragon's tail on one corner (Zhao, 2007, p. 223). An embroidery collected by Chris Hall of the Northern Dynasties (Arthur M. Sackler Museum of Art and Archeology, PKU \& China National Silk Museum, 2009, p. 17) and a piece from Astana of the Sixteen Kingdoms also show dragons which probably can be considered as beast-like dragons (Zhao, 2005, p. 173, fig. 3-4-17).

Embroidered dragon also appears in historical documents, it is often used on official robes, for example, in Xin Tang shu, an important document of the Tang dynasty, it is recorded that a special official named $c i$ was dressed in a robe embroidered with yellow dragons (Song \& Ouyang, 1975, p. 481). According to the poem of the Tang dynasty and documents from Dunhuang, embroidered dragon pattern is also used for curtain (Peng, 1986, vol. 735, p. 1838) or Buddhist canopy (documents from Dunhuang S.1774, S.1642 and P.3432).

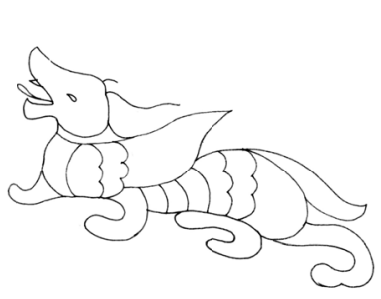

$8 a$

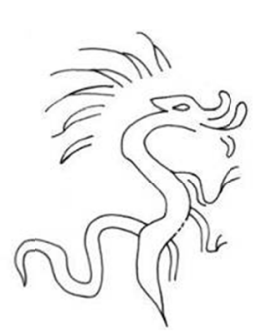

$8 \mathrm{~d}$

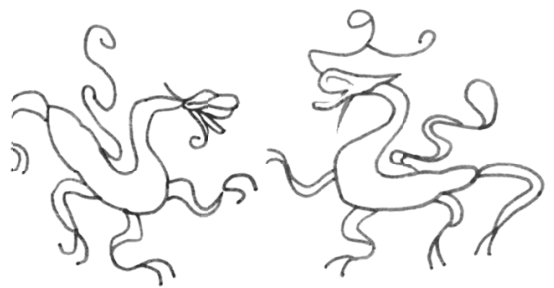

$8 b$

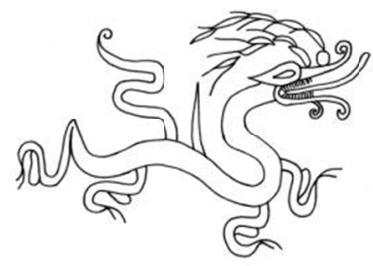

$8 \mathrm{e}$

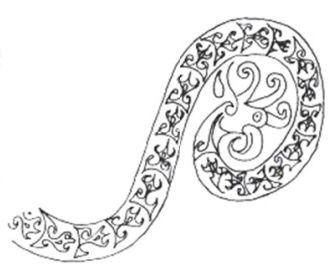

$8 \mathrm{f}$

Figure 8. Dragons on the embroidered textiles found in Noin-Ula and Astana 


\section{(3) Suanni}

In Chinese fairy tales, suanni refers to one of the nine children of dragon, which is a beast similar to lion and fond of smoke and fire. In most cases, this beast is seated. On a garment worn by a color-painted Bodhisattva statue found in Dunhuang there are a pair of animals, being face to face, seated, and similar to lion, with ears and upturned flame-shaped tails. This animal is identified as suanni (Chang, 2001, p. 46, fig. 48). Similar animals appear on two stamps collected by Stein from Xinjiang, also being seated and with flame-shaped tails (Stein, 1921, pl. V). On the upper part of an embroidered bow bag from Dulan or neighboring areas dating to the Northern Wei Dynasty (late 3rdC-early 5thC) now in the collection of China National Silk Museum there are a pair of animals, being face to face, looking like dogs, with long tongues, paws but flame-shaped tails (Figures 9a and $9 \mathrm{~b}$ ). Over the two animals there are clouds. Almost identical animal appears on a dress worn by a maid in the mural in Xu Xianxiu's tomb dating back to the Northern Qi Dynasty (550 AD-577 AD). In a linked pearl roundel enclosed a pair of animals, also being face to face, similar to dog and with flame-shaped tails. Over the heads of the two animals there are two clouds of smoke and something similar to a petal in between the two animals (Taiyuan Institute of Archaeology, 2005, p. 33, fig. 19). This pattern is exactly similar to that on the embroidery. It is possible that animals on the embroidery and in the mural both represent suanni, although they are not similar to lion but flame-shaped tail is a significant mark and in addition both of them have clouds of smoke over their heads, which can be considered as another hint.

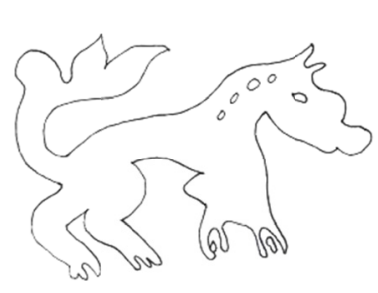

$9 \mathrm{a}$

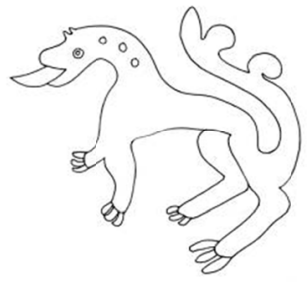

$9 \mathrm{~b}$

Figure 9. Suanni on the embroidered textiles found in Qinghai

\section{(4) Griffins}

Previously we have discussed a beast-style pattern. On a carpet from Noin-Ula there are two strange animals. One looks like an eagle, with eagle hooked beaks and upright ears, spreading its wings and tail (Figure 4a). It is biting a reindeer. The other looks like a horse or a large-scaled dog, with several eagle heads (each with a pair of upright ears) decorated at the ends of the mane and the upright tail (Figure 5). It is attacking a yak with a paw. A wool piece from the same graveyard shows an animal resembling a lion but with wings and horns (Umehara, 1960, fig.50(3). These three animals may all represent griffin. In Central Asian mythology, griffin is legendary creature which is known for guarding treasure and priceless possessions. Eagle heads with upright ears are considered as griffin's head. Griffin can trace its history back to ancient Greek, generally it consists of two groups, one looks like eagle and one looks like lion, but as it was introduced into the Siberian steppes by Scythians many variants were created, for example, beasts look like reindeer, horse or wolf but decorated with eagle heads.

\section{Other Embroidered Animal Patterns in Historical Records}

Animal pattern adopted by embroidered textiles in historical records is more than we have seen on archaeological evidences. About birds, except for phoenixes and five-colored birds there are mandarin ducks, peacocks, geese, orioles, xichi, partridges, luan birds, di birds and etc.; about beasts, besides dragons, tigers and horses there are kirin and pixie. Here are some examples from historical records:

(1) Mandarin ducks

In China, mandarin duck is considered as a symbol of a happy marriage and it is very popular in the Tang dynasty. In the poems of Tang, there are many descriptions about mandarin ducks executed by embroidering on clothing, for instance, a gauze shirt (Peng, 1986, vol. 328, p. 810; vol. 896, p. 2180), another gauze skirt (Peng, 1986, vol. 506, p. 1280) and a dancing dress (Peng, 1986, vol. 894, p. 2174). Except for clothing, embroidered mandarin ducks also decorate household items, especially quilts (Peng, 1986, vol. 892, p. 2170) and bed curtains (Peng, 1986, vol. 666, p. 1675; vol. 894, p. 2176). 


\section{(2) Peacocks}

Peacock should have been a common pattern for embroidery in the Tang dynasty. It is recorded that fans embroidered with peacocks were used in formal occasions at imperial court during Kaiyuan period (713-741) (Liu, 1975, p. 1866) and peacocks executed with gold threads in couching stitch on a belt and a gauze shirt are described in a poem written by Huangpu Song (Peng, 1986, vol. 369, p. 920) and a poem written by Du Fu (Peng, 1986, vol. 25, p. 93).

\section{(3) Geese}

Goose is also common to see on embroidery in the Tang dynasty. According to some poems of Tang, there are geese executed with silver threads on gauze shirt (Peng, 1986, vol. 302, p. 761), geese executed with gold threads on damask or gauze (Peng, 1986, vol. 735, p. 1838) and geese executed with purple-colored threads on robe (Peng, 1986, vol. 700, p. 1766), etc.

\section{(4) Orioles}

There are few examples of embroidered oriole, only in a poem written by Sun Guangxian, it is mentioned that a shirt was embroidered with an oriole (Peng, 1986, vol. 897, p. 2184).

\section{(5) Xichi}

Xichi is a purple bird similar to but larger than mandarin duck. In a poem written by Liu Jian it is described that on a ground of gauze there is a pair of newly finished embroidered xichi (Peng, 1986, vol. 766, p. 1900), and in a poem written by Bai Juyi mentions a shirt embroidered with xichi (Peng, 1986, vol. 438, p. 1086).

\section{(6) Partridges}

Partridge is similar to but smaller than chicken. In a poem written by Wen Tingjun it is described that on a jacket made of gauze several pairs of partridges were embroidered with gold threads in couching stitch (Peng, 1986, vol. 891, p. 2167).

\section{(7) Luan birds}

In China, luan is a mythical bird like the phoenix. Luan bird as a pattern for embroidery appears in a poem written by Lu Zhaolin and a poem written by Wei Chengban, in which it is mentioned a bed-curtain embroidered with luan bird (Peng, 1986, vol. 41, p. 133) and a gauze shirt decorated with luan bird embroidered with gold threads (Peng, 1986, vol. 895, p. 2167).

\section{(8) $D i$ birds}

$D i$ is a long-tailed pheasant and usually used as a pattern on the formal dress for the empress, imperial concubines or women given a title or rank by the emperor. In Tang liu dian [Six Administrative Regulations and Rules of the Tang Government] it is specified that women in the palace should wear long dark blue-colored gauze dress embroidered with di bird (Li, 1992, p. 341); besides dress in Jiu Tang shu [Old Book of Tang History.] also specified bixi (a cloth used to cover knees hanging from the waist) should be embroidered with $d i$ bird (Liu, 1975, p. 1956).

\section{(9) Kirin}

Kirin is an auspicious animal in Chinese mythology and also often used as a pattern for embroidery. According to the poems of Tang, kirin is usually executed in gold or silver threads in couching stitch, for example, in a poem written by $\mathrm{Du} \mathrm{Fu}$ it is described that beauties dressed in gauze dresses embroidered with gold peacock and silver kirin are enjoying the beauty of spring near Qu River in suburban Chang'an (Peng, 1986, vol. 25, p. 93), and a poem written by Rong Yu mentions an attendant is carrying a bolt of silk embroidered with gold kirin (Peng, 1986, vol. 270, p. 673).

(10) Pixie

Pixie is also an auspicious animal in Chinese mythology. It is similar to deer but with long tail and two horns. A poem written by Lin Kuan mentions pixie probably embroidered with gold threads in couching stitch (Peng, 1986, vol. 606, p. 1536), and in Xin Tang shu it is recorded that pixie executed in embroidery is used as a pattern on an official robe (Song \& Ouyang, 1975, p. 530). Pixie used on the robe of a military officer is a symbol of officer's rank and also valor.

\section{Conclusion}

The archaeological evidences from the Silk Road show that animal pattern widely appears on the embroidered textiles unearthed from Shanpula, Niya, Zhaguluke, Astana in Xinjiang province, the Mogao Grottoes in Gansu 
province, Dulan or neighboring areas in Qinghai province, Famen Temple in Shaanxi province and Noin-Ula in Mongolia. As a common motif it is particularly rich in variety. Generally, animals on the embroideries from the Silk Road can be categorized into animals of the real world and animals of the imaginary world. Animals of the real world consists of a range of animals, including birds, butterflies, horses, antelopes, deer, yaks, tigers, fish and turtles. Some animals match the records in historical documents and show their popularity during this period. Among them, most of the birds are hard to be identified but they are nearly always closely connected to flowers. As a pattern, butterfly appears as late as the Tang dynasty, especially during the period of the late Tang to Five Dynasties. It also usually combines with flowers and flying birds to create the scene of a spring day. Herbivorous animals like horses, antelopes, deer (especial reindeers) and yaks and carnivorous animals like tigers which are regular seen on the grasslands are mostly found on the wool textiles from Noin-Ula and Shanpula; so are aquatic animals like fish and turtles. Imaginary animals also appear on the embroideries dating to the Han and Tang dynasties unearthed from the Silk Road, including phoenixes, wuseniao, double-headed birds, dragons and suanni which play an important role in Chinese mythology or appear in historical documents and significant legendary creature griffin in Central Asian mythology. Mostly, the imaginary animal patterns are related to special cultures. In addition, animal pattern adopted by embroidered textiles in historical records is more than we have seen on archaeological evidences. About birds, except for phoenixes and five-colored birds there are mandarin ducks, peacocks, geese, orioles, xichi, partridges, luan birds, di birds and etc.; about beast, besides dragons, tigers and horses there are kirin and pixie.

\section{Acknowledgements}

This work was financially supported by the Social Science Foundation of Jiangsu Province (No. 14LSC002) and the Fundamental Research Funds for the Central Universities (No. JUSRP11469).

\section{References}

Arthur, M. Sackler Museum of Art and Archeology, PKU \& China National Silk Museum. (2009). Memories of Central Asian. Beijing/Hangzhou: Arthur M. Sackler Museum of Art and Archeology, PKU /China National Silk Museum.

Chang, S. (2001). Album of Costumes in Past Dynasties Shown in the Murals at Dunhuang. Beijing: China Light Industry Publishing House.

Chen, Z. y. (1996). The Lacquer Ware of the Chu State, Qin and Han Dynasties. Wuhan: Hubei Fine Arts Publishing House.

China National Silk Museum \& State History Museum in Moscow. (2007). Road of Silk: 5000 Years of the Art of Silk. Hangzhou: China National Silk Museum.

Duan, W. j. (Ed.). (2002). Complete Works of the Murals at Dunhuang. Tianjin: Tianjin People's Fine Arts Publishing House.

Kuang, Y. h. (2013). Study on Embroideries of the Han and Tang Dynasties (206BC-907AD) Unearthed from the Northwest China (Unpublished doctoral dissertation). Donghua University, Shanghai, China.

Li, L. f. (1992). Six Administrative Regulations and Rules of the Tang Government. Beijing: Zhonghua Book Company.

Li, X. (Ed.). (2006). Selected Treasures of Turfan Relics. Shanghai: Shanghai Cishu Press.

Liu, X. (1975). Old Book of Tang History. Beijing: Zhonghua Book Company.

Ma, L. q. (2005). An Archaeological Study on the History and Culture of an Ancient Nationality Xiongnu. Hohhot: Inner Mongolia University Press.

Museum of Xinjiang Uygur Autonomous Region \& Xinjiang Institute of Archaeology. (2001). Sampula in Xinjiang of China: Revelation and Study of Ancient Khotan Civilization. Urumqi: Xinjiang Peoples Publishing House.

Peng, D. q. (Ed.). (1986). A Full Collection of Poems of the Tang Dynasty. Shanghai: Shanghai Classics Publishing House.

Rudenk, S. I. o. (1969). Die Kultur der Hsiung-nu und die Hügelgräber von Noin Ula.R. Bonn: Habelt.

Shaanxi Provincial Institute of Archaeology. (2001). The Mausoleum of Western Han Emperor Liu Qi. Chongqing: Chongqing Press.

Song, Q., \& Ouyang, X. (1975). New Book of Tang History. Beijing: Zhonghua Book Company. 
Stein, A. (1921). Serindia: Detailed Report of Explorations in Central Asia and Westernmost China. Oxford: Clarendon Press.

Taiyuan Institute of Archaeology. (2005). The Tomb of Xu Xianxiu Dated to the Northern Qi Dynasty. Beijing: Cultural Relics Publishing House.

Umehara, S. (1960). Studies of Noin-Ula Finds in North Mongolia. Tokyo: The Toyo Bunko.

Wang, X. (2001). Condition Report and Preliminary Analysis of Textiles Found in Famen Temple. In F. Zhao (Ed.), Wang Xu \& Textile Archaeology in China. Hong Kong: ISAT/Costume.

Xinjiang Cultural Relics Administration Bureau et al. (1999). Relics and Ancient Sites in Xinjiang. Urumqi: Xinjiang Art Photography Press.

Yu, Y. (2010). A Study of Wool Costumes and Textiles Unearthed from Shanpula Graveyard (Unpublished doctoral dissertation). Donghua University, Shanghai, China.

Zhang, J. (2004). A Study on the Pattern of Clouds and Beasts on Lacquer Works of the Han Dynasty. In The Ninth Annual Symposium of Chinese Institute of Han Dynasty's Art. Beijing: China Social Press.

Zhang, L. h. (Ed.). (2002). Painted Pottery Found in Gansu. Chongqing: Chongqing Press.

Zhao, F. (1999). Treasures in Silk. Hong Kong: ISAT/Costume.

Zhao, F. (Ed.). (2005). The General History of Chinese Silk. Suzhou: Suzhou University Press.

Zhao, F. (Ed.). (2007). Textiles from Dunhuang in UK Collections. Shanghai: Donghua University Press.

Zhao, F. (Ed.). (2010). Textiles from Dunhuang in French Collections. Shanghai: Donghua University Press.

Zhao, F., \& Yu, Z. y. (Eds.). (2000). Legacy of the Desert King. Hong Kong: ISAT/COSTUME SQUARD LTD.

Королькова, Е. Ф. (2006). Властители степей. Санкт-Петербург: Государственный Эрмитаж.

Лубо-Лесниченко, Е. И. (1961). Древние китайские шелковые ткани и вышивки V в. до н.э.-ІІІ в. н.э. $в$ собрании Государственного Эрмитажа. Каталог. Ленинград: Izd-vo Gos. Ermitazha.

\section{Copyrights}

Copyright for this article is retained by the author(s), with first publication rights granted to the journal.

This is an open-access article distributed under the terms and conditions of the Creative Commons Attribution license (http://creativecommons.org/licenses/by/3.0/) 